\title{
МОДЕЛЬ МЕТОДИКИ ФОРМИРОВАНИЯ ИССЛЕДОВАТЕЛЬСКОЙ КОМПЕТЕНТНОСТИ СТУДЕНТОВ-БИОЛОГОВ В ПРОЦЕССЕ ИЗУЧЕНИЯ ЖИВОТНЫХ
}

\section{METHODOLOGICAL MODEL FOR THE FORMATION OF RESEARCH COMPETENCE OF BIOLOGY STUDENTS IN THE PROCESS OF ANIMAL STUDIES}

\section{F. Miniyarov}

A. Yaitsky

Summary: The use of modern algorithms of organization of research activities for biology students during studying at a University allows, in perspective, to prepare professional biologists who have the ability to continuously self-develop, self-educate and generate scientific ideas. The analysis of classical and modern scientific methods of forming research competence among students allowed us to develop a criteriabased assessment system and a methodological model for establishing of research competence of biology students during of animal research. The model contains several components: target, scope, procedural and performance-evaluation. The pedagogical experiment was aimed at implementation of these components into the educational process in order increase the level of research competence among biology students. An important feature of the organization of research activities of biology students is the studies of living zoo species during laboratory exercises and educational research projects. The results of the study showed that our hypothesis is fully confirmed. We experimentally proved the effectiveness of developed methodology for the formation of students' research competence, which was confirmed by a statistically significant increase in the level of capacity.

Keywords: research activities, research competence, questionnaire, expert evaluation method, self-assessment, biology students.
Минияров Фарит Талгатович к.б.н., дочент, ФГБОУ ВО «Астраханский государственный университет»

fminiyarov@mail.ru

Яицкий Андрей Степанович

старший преподаватель, ФГБОУ ВО «Самарский государственный сочиально-педагогический университет» yaitsky@sgspu.ru

Аннотация: Использование современных алгоритмов организации исследовательской работы студентов-биологов при обучении в вузе позволяет, в дальнейшем, подготовить биологов-профессионалов, обладающих способностью к непрерывному саморазвитию, самообразованию и генерации научных идей. Анализ классических и современных научных подходов к процессу формирования исследовательской компетентности у студентов позволил нам разработать критериально-оценочный аппарат и модель методики формирования исследовательской компетентности студентов-биологов в процессе изучения животных, содержащую целевой, содержательный, процессуальный и результативно-оценочный компоненты. Педагогический эксперимент был направлен на их внедрение в учебный процесс для повышения уровня сформированности исследовательской компетентности у студентов-биологов. Важной особенностью организации исследовательской работы студентов-биологов является изучение живых зо0объектов в ходе лабораторных работ и учебно-исследовательских проектов. Полученные результаты исследования показали, что выдвинутая гипотеза полностью подтвердилась. Нами экспериментально доказана эффективность разработанной методики формирования исследовательской компетентности у студентов-биологов, что подтвердилось статистически значимым повышением уровня сформированности.

Ключевые слова: исследовательская деятельность, исследовательская компетентность, анкетирование, метод экспертных оценок, самооценка, студенты-биологи.

но-исследовательская деятельность, а среди возможных областей профессиональной деятельности фигурирует такая область как «Образование и наука».

Выпускники высших учебных заведений должны уметь анализировать, сравнивать, квалифицировать, обобщать, быстро находить нужную информацию, логически мыслить, использовать новые научные знания в своей профессиональной деятельности, планировать, организовывать и вести исследовательскую и инновационную деятельность [1-5]. В связи с этим актуальным становится разработка средств, механизмов, технологий, подходов к организации эффективной исследовательской деятельности студентов в вузах. Продуктивным 
путем реализации этой задачи является метод моделирования [6-8].

Однако, нами выявлены противоречия: быстро меняющиеся требования общества к подготовке конкурентоспособного профессионала и требования работодателей к подготовке высококвалифицированных специалистов, способных к проведению исследований и созданию новых технологий часто противоречат реальной ситуации с уровнем подготовки выпускников вузами [9-11]. В этом заключается проблема исследования.

Целью нашего исследования явилось теоретическое обоснование, разработка и внедрение в учебный процесс вуза методики формирования исследовательской компетентности у студентов-биологов [11].

Гипотеза исследования: процесс формирования исследовательской компетентности у студентов-биологов будет более эффективным, если будут разработаны и внедрены в учебный процесс методика формирования исследовательской компетентности и критериальнооценочный аппарат уровня сформированности компетентности [11].

\section{Материал и методика исследований}

Для достижения цели, нами использовались следующие методы педагогических исследований: теоретические методы (анализ педагогической и специальной литературы по исследуемой проблеме; изучение педагогического опыта и практической работы преподавателей вузов) [6; 12; 13]; эмпирические методы (педагогическое наблюдение, анкетирование, беседа, уровневый метод, метод экспертных оценок, опытно-экспериментальная работа) $[10 ; 11 ; 14-16]$; методы статистической обработки результатов эксперимента $[17 ; 18]$.

В ходе исследования была разработана модель методики формирования исследовательской компетентности, обеспечивающая управление проектной деятельностью студентов-биологов в учебном процессе за счет организации систематической профессионально направленной исследовательской деятельности [11]. Основные компоненты разработанной модели - целевой, содержательный, процессуальный, результативно-оценочный.

Целевым компонентом разработанной модели определяются ее цель и задачи. Целью является формирование исследовательской компетентности студентовбиологов в процессе изучения животных. Для достижения данной цели необходимо решить следующие задачи: сформировать у учащихся знания, умения, ценностные ориентации и готовность применять сформированные знания, умения, ценностные установки при проведении зоологических исследований.

Содержательный компонент разработанной методики определяет основное содержание учебного курса зоологии. Данный компонент представлен 3 элементами: когнитивным, деятельностным и ценностно-ориентационным.

- Когнитивный элемент включает в себя систему зоологических знаний: о морфологии, анатомии, систематике, многообразии, этологии животных, методах зоологических исследований.

- Деятельностный элемент включает в себя систему умений, необходимых для успешного осуществления исследовательской деятельности по зоологии: умения формулировать тему, актуальность, выделять проблему, формулировать цель, объект, предмет, задачи, гипотезу исследования, выбирать и применять методы, работать с источниками информации, анализировать результаты, делать выводы, оформлять результаты.

- Ценностно-ориентационный элемент направлен на осознание студентами необходимости охраны животного мира и сохранения зоологического разнообразия, соблюдение этических норм при проведении лабораторных исследований.

Процессуальный компонент отражает процесс организации учебной работы по изучению животных и содержит:

- Формы изучения животных (лекционные, лабораторные, семинарские занятия, полевые исследования и др.).

- Методы формирования исследовательской компетентности (наблюдение, распознавание и определение объектов, эксперимент, анализ, синтез, сравнение, классификация и др.).

- Средства формирования исследовательской компетентности (живые зоообъекты; информационные средства - учебники, учебные пособия, методические рекомендации, монографии, отечественные и зарубежные научные журналы, материалы конференций, сборники статей, интернет-ресурсы и др.; технические средства - компьютеры, световые и цифровые микроскопы, лабораторное оборудование и др.).

- Технологии формирования исследовательской компетентности (технология проектного обучения, технология организации учебно-исследовательской деятельности, технология проблемного обучения, информационные технологии).

В ходе реализации разработанной модели, была организована лаборатория экспериментальной зоологии на базе технопарка Астраханского государственного университета. Основные задачи и функции созданной лаборатории: проведение научных исследований в об- 
ласти зоологии; обеспечение материалами и биологическими объектами для проведения исследований; организация работы комплекса оборудования для экспериментальной зоологии; подготовка и издание научных публикаций, результаты для написания которых получены на базе лаборатории [19]. Лаборатория экспериментальной зоологии стала базовой для студентов-биологов, проходивших курс лабораторных работ по учебной дисциплине «Зоология беспозвоночных» и учебную практику по биоразнообразию [20].

Процессуальный компонент включает в себя этапную реализацию модели методики формирования исследовательской компетентности у студентов-биологов.

- Этапы формирования исследовательской компетентности:

1 этап (начальный) включает в себя следующие стадии:

- мотивационно-целевая стадия: перед студентами ставится цель: что они должны узнать, для чего им это нужно (для успешного написания курсовых работ, выпускных квалификационных работ, сдачи экзаменов, зачётов и дифференцированных зачётов, участия в конференциях);

- когнитивная стадия: формирование зоологических знаний, ознакомление с методами исследования;

- практическая стадия: овладение исследовательскими умениями в рамках усовершенствованных лабораторных работ по зоологии беспозвоночных, дающих начальные навыки исследовательской работы с зоообъектами. Лабораторные работы проводились одновременно с изучением теоретического курса в течение первых двух семестров обучения. Главная особенность лабораторных работ в представленной модели - структура и содержание лабораторных работ в виде учебно-исследовательского проекта, кроме этого в них максимально использовались живые 30ообъекты.

2 этап (базовый) - для формирования исследовательской компетентности у студентов-биологов была организована творческая исследовательская работа в рамках реализации учебно-исследовательских проектов по прикладной зоологии. Данная исследовательская работа осуществлялась во время прохождения учебной практики по биоразнообразию во втором семестре. Учебно-исследовательские проекты представляли собой исследовательскую работу студентов, ориентированную на наблюдение и эксперименты с живыми зоообъектами в естественной среде обитания и в лабораторных условиях.
Результативно-оценочный компонент выступает заключительным в разработанной модели и предполагает повышение уровня сформированности исследовательской компетентности студентов-биологов в процессе изучения животных.

Оценивание сформированности исследовательской компетентности у студентов-биологов на обоих этапах реализации методики проводилось уровневым методом и методом экспертных оценок с использованием специальных анкет (по И.В. Клещевой, с изменениями) [21].

Нами был разработан критериально-оценочный аппарат для анкетирования студентов: входное анкетирование (самооценка) и итоговое анкетирование (экспертная оценка) (табл. 1).

Для правильного оценивания необходимо соблюдать ряд правил и принципов:

- план исследований в проектах за отчетный период одинаковый для всех студентов, как и, соответственно, ожидаемый результат;

- открытость: студенты ознакомлены как с исследовательскими задачами, поставленными перед ними, так и со способами контроля и оценки полученных результатов;

- неизменность правил: однозначность, открытость и окончательность в оценивании результатов.

При оценивании результатов рассматривается не только уровень достигнутых результатов, но и затраченные усилия $[10 ; 11 ; 21]$.

Базой исследования являлся Астраханский государственный университет, в исследовании приняло участие 182 студента очной и очно-заочной форм обучения (табл. 2).

Статистический анализ достоверности различий полученных результатов по уровню сформированности исследовательской компетентности был проведен с использованием критерия $X^{2}$ Пирсона $\left(X^{2}\right)$ в программе Statistica 13.5 (2018) (TIBCO Software Inc.) [18].

\section{Результаты исследования и их обсужление}

На первом этапе исследования мы оценивали уровень сформированности исследовательской компетентности у студентов после курса лабораторных работ по изучению беспозвоночных животных, на втором этапе после прохождения учебной практики и выполнения учебно-исследовательских проектов по прикладной зоологии. Результаты входного и итогового анкетирований студентов представлены в табл. 3.

На первом этапе, по результатам входного анкети- 
Таблица 1.

Критериально-оценочный аппарат

для анкетирования студентов

\begin{tabular}{|c|c|c|c|c|}
\hline \multirow[b]{2}{*}{ Вид оценки } & \multicolumn{4}{|c|}{ Уровень сформированности исследовательской компетентности } \\
\hline & $\begin{array}{c}\text { Высокий } \\
\text { (31-50 баллов) }\end{array}$ & $\begin{array}{c}\text { (редний } \\
\text { (21-30 баллов) }\end{array}$ & $\begin{array}{c}\text { Низкий } \\
\text { (11-20 баллов) }\end{array}$ & $\begin{array}{l}\text { Начальный } \\
\text { (0-10 баллов) }\end{array}$ \\
\hline Самооценка & $\begin{array}{l}\text { Могу рассказать, как это } \\
\text { делать, и научить другого }\end{array}$ & $\begin{array}{l}\text { Могу осуществить на практике, } \\
\text { действуя по образцу и твор- } \\
\text { чески }\end{array}$ & Знаю теорию & Прошу помощи \\
\hline Оценка эксперта & $\begin{array}{l}\text { Компетентность сформирована } \\
\text { на высоком уровне }\end{array}$ & $\begin{array}{l}\text { Компетентность сформирована } \\
\text { удовлетворительно }\end{array}$ & $\begin{array}{l}\text { Компетент-ность сфор- } \\
\text { мирована слабо }\end{array}$ & $\begin{array}{l}\text { Компетент-ность не сфор- } \\
\text { мирована }\end{array}$ \\
\hline
\end{tabular}

Таблица 2.

Количество студентов, задействованных в эксперименте на различных этапах и периодах обучения

\begin{tabular}{|c|c|c|c|c|c|c|}
\hline \multirow[b]{2}{*}{ № } & \multirow{2}{*}{$\begin{array}{c}\text { Этапы формирования } \\
\text { исследовательской } \\
\text { компетентности }\end{array}$} & \multicolumn{4}{|c|}{ Период обучения студентов в университете } & \multirow[b]{2}{*}{ Итого } \\
\hline & & $2015-2020$ гг.* & $2016-2020$ гг. $^{* *}$ & $2017-2021$ гг. ${ }^{* *}$ & $2018-2022$ гг. ${ }^{* *}$ & \\
\hline 1 & 1 этап (начальный) & 14 & 26 & 15 & 43 & 98 \\
\hline 2 & 2 этап (базовый) & - & 26 & 15 & 43 & 84 \\
\hline & Итого: & 14 & 52 & 30 & 86 & 182 \\
\hline
\end{tabular}

Примечание. * - очно-заочная форма обучения, ** - очная форма обучения.

рования, было определено, что большинство студентов имели начальный и низкий уровни сформированности исследовательской компетентности. В зависимости от года исследований, доля таких студентов составляла от 66,7 до $88,3 \%$ от общего количества студентов. После прохождения курса лабораторных работ по зоологии беспозвоночных, доля студентов с высоким и средним уровнями сформированности исследовательской компетентности стала составлять от 57,2 до $72,1 \%$ от общего количества. Эти студенты хорошо понимали роль и значение лабораторных работ, имели стабильный интерес к лабораторным заданиям и обладали достаточными знаниями для их выполнения и оформления. Статистический анализ полученных результатов уровневого распределения студентов по годам с помощью критерия Пирсона $\chi^{2}$ показал недостаточную значимость распределения студентов по уровням в 2016 и в 2018 гг. (значения $\chi_{\text {эмпир. }}^{2}$ меньше $\chi_{\text {крит. }}^{2}$ ) (табл. 3). Но при этом, в 2017, 2019 гг. и по среднегодовому расчету, мы получили статистически достоверное отличие по уровневому распределению студентов в начале и в конце курса $\left(\chi_{\text {эмпир }}^{2}\right.$ 15,$065 ; 34,669$ и 11,632 при $\chi_{\text {крит. }}^{2} 11,345$ при уровне значимости $\mathrm{p}=0,01$ ) (табл. 4). Таким образом, мы можем утверждать, что проведенный курс лабораторных работ на начальном этапе позволяет сформировать у 65\% студентов-биологов высокий и средний уровни исследовательской компетентности.

На втором этапе, после прохождения практики по зоологии беспозвоночных и выполнения учебно-исследовательских проектов, количество студентов с начальным и низким уровнями сформированности исследователь- ской компетентности стало составлять от 11,5 до 13,4\% от общего количества студентов; большинство составляли студенты с высоким и средним уровнями исследовательской компетентности. Эта группа студентов умела ставить цели и задачи, работать с живыми зоообъектами, использовать прикладные методы исследований, обрабатывать и представлять полученные результаты исследований, и в итоге успешно реализовывать учебно-исследовательские проекты по зоологии. Статистический анализ полученных результатов с помощью критерия Пирсона $\chi^{2}$ показал достоверное отличие по уровневому распределению студентов в начале и в конце практики на протяжении всего исследуемого периода $\left(\chi_{\text {эмпир. }}^{2}\right.$ 18,$064 ; 11,105 ; 16,199 ; 13,037$ при $\chi_{\text {крит. }}^{2} 11,345$ или 7,815 при уровне значимости $p=0,01$ или $p=0,05)$ (табл. 4). Таким образом, мы можем утверждать, что выполнение учебно-исследовательских проектов по зоологии на втором этапе позволяет сформировать у 88,5\% студентов-биологов высокий и средний уровни исследовательской компетентности.

\section{ЗакАючение}

Анализ современных научных подходов к процессу формирования исследовательской компетентности у студентов вузов позволил нам разработать критериально-оценочный аппарат и модель методики формирования исследовательской компетентности, содержащую целевой, содержательный, процессуальный и результативно-оценочный компоненты. Дальнейшая опытноэкспериментальная работа была направлена на внедрение разработанной методики в учебный процесс и 
Таблица 3.

Результаты входного и итогового анкетирования студентов после двух этапов исследования

\begin{tabular}{|c|c|c|c|c|c|c|c|c|c|c|c|c|}
\hline \multirow{2}{*}{ № } & \multirow{2}{*}{ Уровень сформированности } & \multirow{2}{*}{ Анкетирование } & \multicolumn{2}{|c|}{2016 г. } & \multicolumn{2}{|c|}{2017 г. } & \multicolumn{2}{|c|}{2018 г. } & \multicolumn{2}{|c|}{2019 г. } & \multicolumn{2}{|c|}{ Среднее } \\
\hline & & & $\mathrm{N}$ & $\%$ & $\mathrm{~N}$ & $\%$ & $\mathrm{~N}$ & $\%$ & $\mathrm{~N}$ & $\%$ & $\mathrm{~N}$ & $\%$ \\
\hline \multicolumn{13}{|c|}{1 этап (лабораторные работы) } \\
\hline \multirow[t]{2}{*}{1} & \multirow[t]{2}{*}{ Высокий } & Входное & 1 & 7,1 & 2 & 7,7 & 2 & 13,3 & 1 & 2,3 & 1,5 & 7,6 \\
\hline & & Итоговое & 2 & 14,3 & 7 & 26,9 & 3 & 20,0 & 10 & 23,3 & 5,5 & 21,1 \\
\hline \multirow[t]{2}{*}{2} & \multirow[t]{2}{*}{ Средний } & Входное & 2 & 14,3 & 3 & 11,5 & 3 & 20,0 & 4 & 9,3 & 3,0 & 13,8 \\
\hline & & Итоговое & 6 & 42,9 & 11 & 42,3 & 6 & 40,0 & 21 & 48,8 & 11,0 & 43,5 \\
\hline \multirow[t]{2}{*}{3} & \multirow[t]{2}{*}{ Низкий } & Входное & 5 & 35,7 & 12 & 46,2 & 3 & 20,0 & 21 & 48,8 & 10,3 & 37,7 \\
\hline & & Итоговое & 5 & 35,7 & 7 & 26,9 & 4 & 26,7 & 10 & 23,3 & 6,5 & 28,1 \\
\hline \multirow[t]{2}{*}{4} & \multirow[t]{2}{*}{ Начальный } & Входное & 6 & 42,9 & 9 & 34,6 & 7 & 46,7 & 17 & 39,5 & 9,8 & 40,9 \\
\hline & & Итоговое & 1 & 7,1 & 1 & 3,8 & 2 & 13,3 & 2 & 4,7 & 1,5 & 7,2 \\
\hline & & Итого за год: & 14 & 100,0 & 26 & 100,0 & 15 & 100,0 & 43 & 100,0 & 24,5 & 100,0 \\
\hline \multicolumn{13}{|c|}{2 этап (учебно-исследовательские проекты) } \\
\hline \multirow[t]{2}{*}{1} & \multirow[t]{2}{*}{ Высокий } & Входное & - & - & 7 & 26,9 & 3 & 20,0 & 10 & 23,3 & 6,7 & 23,4 \\
\hline & & Итоговое & - & - & 21 & 80,8 & 12 & 80,0 & 28 & 65,1 & 20,3 & 75,3 \\
\hline \multirow[t]{2}{*}{2} & \multirow[t]{2}{*}{ Средний } & Входное & - & - & 11 & 42,3 & 6 & 40,0 & 21 & 48,8 & 12,7 & 43,7 \\
\hline & & Итоговое & - & - & 2 & 7,7 & 1 & 6,7 & 10 & 23,3 & 4,3 & 12,5 \\
\hline \multirow[t]{2}{*}{3} & \multirow[t]{2}{*}{ Низкий } & Входное & - & - & 7 & 26,9 & 4 & 26,7 & 10 & 23,3 & 7,0 & 25,6 \\
\hline & & Итоговое & - & - & 1 & 3,8 & 1 & 6,7 & 3 & 7,0 & 1,7 & 5,8 \\
\hline \multirow[t]{2}{*}{4} & \multirow[t]{2}{*}{ Начальный } & Входное & - & - & 1 & 3,8 & 2 & 13,3 & 2 & 4,7 & 1,7 & 7,3 \\
\hline & & Итоговое & - & - & 2 & 7,7 & 1 & 6,7 & 2 & 4,7 & 1,7 & 6,3 \\
\hline & & Итого за год: & - & - & 26 & 100,0 & 15 & 100,0 & 43 & 100,0 & 28,0 & 100,0 \\
\hline
\end{tabular}

Примечание. $\mathrm{N}$ - количество студентов; \% - доля от общего количества студентов.

Таблица 4.

Результаты статистического сравнения входного и итогового анкетирования студентов по годам

\begin{tabular}{|c|c|c|c|}
\hline Годы & $\begin{array}{c}\text { Критерий Пирсона } \\
\left(\chi^{2} э \text { мпир.) при df = } 3\right.\end{array}$ & $\begin{array}{l}\text { Критерий Пирсона } \\
\left(\chi^{2} \text { крит.) при df = } 3\right.\end{array}$ & Уровень значимости \\
\hline \multicolumn{4}{|c|}{1 этап (лабораторные работы) } \\
\hline 2016 & 5,905 & 7,815 при $p<0,05$ & $p \leq 0,117$ \\
\hline 2017 & 15,065 & 11,345 при $p=0,01$ & $p \leq 0,002$ \\
\hline 2018 & 4,121 & 7,815 при $p<0,05$ & $p \leq 0,249$ \\
\hline 2019 & 34,669 & 11,345 при $p=0,01$ & $p \leq 0,001$ \\
\hline Среднее & 11,632 & 11,345 при $p=0,01$ & $p \leq 0,009$ \\
\hline \multicolumn{4}{|c|}{2 этап (учебно-исследовательские проекты) } \\
\hline 2017 & 18,064 & 11,345 при $p=0,01$ & $p \leq 0,001$ \\
\hline 2018 & 11,105 & 7,815 при $p=0,05$ & $p \leq 0,012$ \\
\hline 2019 & 16,199 & 11,345 при $p=0,01$ & $p \leq 0,002$ \\
\hline Среднее & 13,037 & 11,345 при $p<0,01$ & $p \leq 0,005$ \\
\hline
\end{tabular}

Примечание. df - число степеней свободы. 
на оценку влияния её реализации на формирование исследовательской компетентности у студентов-биологов. Основная особенность организации исследовательской работы студентов заключалась в том, что изучение живых зоообъектов осуществлялось не только в ходе лабораторных работ, но и при выполнении учебно-исследовательских проектов.
Полученные результаты исследований показали, что выдвинутая нами гипотеза полностью подтвердилась. Мы экспериментально доказали эффективность разработанной методики формирования исследовательской компетентности, что подтвердилось статистически значимым повышением уровня сформированности названной компетентности у студентов-биологов.

\section{ЛИТЕРАТУРА}

1. Лобова Г.Н. Теоретические и технологические основы профессиональной подготовки студентов к научно-исследовательской деятельности: автореф. дис. ... д-ра пед. наук: 13.00.08. М., 2002. 40 с.

2. Горшкова 0.0. Подготовка будущих инженеров к исследовательской деятельности. Тюмень: ТюмГНГУ, 2013. 272 с.

3. Терехина 0.С. Формирование исследовательских умений студентов инженерных специальностей вузов: дис. ... канд. пед. наук. Нижний Новгород, 2010. $181 \mathrm{c}$.

4. Лернер И.Я. Дидактические основы методов обучения. М.: Педагогика, 1981. 186 с.

5. Бабанский Ю.К. Оптимизация учебно-воспитательного процесса: Методические основы. М.: Просвещение, 1982. 192 с.

6. Бондаревская Е.В. Теория и практика личностно-ориентированного образования. Ростов-на-Дону: Изд-во РГПУ, 2000. 352 с.

7. Скибицкий Э.Г., Толстова И.Э., Шефель В.Г. Методика профессионального обучения: уч. пос. Новосибирск: НГАУ, 2008. 166 с.

8. Белых С.Л. Управление исследовательской активностью студента: методическое пособие для преподавателей вузов и методистов / под ред. А.С. 06ухова. Ижевск: УдГУ, 2008. 72 с.

9. Хуторской А.В. Практикум по дидактике и современным методикам обучения: учеб. пособие. СПб.: Питер, 2004. 541 с.

10. Кушнер Ю.З. Методология и методы педагогического исследования. Могилев: МГУ им. А.А. Кулешова, 2001. 68 с.

11. Гараева Е.А. Организация исследовательской работы бакалавров: учебное пособие. Оренбург: Оренбургский государственный университет, 2012.212 с.

12. Безуглов И.Г., Лебединский В.В., Безуглов А.И. Основы научного исследования. М.: Изд-во: Академический проект, 2008. 208 с.

13. Пастухова И.П., Тарасова Н.В. Основы учебно-исследовательской деятельности студентов: учеб.-метод. пособие для студ. сред. проф. уч. заведений. М.: Изд. центр «Академия», 2010. 160 c.

14. Поддьяков А.Н. Методологические основы изучения и развития исследовательской деятельности // Исследовательская деятельность учащихся в современном образовательном пространстве / под ред. А.С. Обухова. М.: НИИ школьных технологий, 2006. С. 51-58.

15. Сотник В.Г. Формирование исследовательской компетентности студентов в процессе организации самостоятельной проектно-исследовательской деятельности: дис. ... канд. пед. наук. СПб., 2006. 169 с.

16. Середенко П.В. Формирование готовности будущих педагогов к обучению учащихся исследовательским умениям и навыкам: автореф. дис. ... д-ра пед. наук. М., 2008. 39 C.

17. Плохинский Н.А. Математические методы в биологии. М.: МГУ, 1978. 205 с.

18. Матвеева Н.М., Валеева А.А. Статистическая обработка результатов полевых агрохимических исследований с помощью пакета STATGRAPHICS PLUS for Windows. Казань: Казанский ун-т, 2012. 63 с.

19. Минияров Ф.Т. Особенности организации зоологических исследований для студентов-биологов // Зоологические экскурсии по Астраханской области и Тебердинскому заповеднику: материалы научно-практической конференции. Астрахань: Издательский дом «Астраханский университет», 2019. С. 7-8.

20. Miniyarov F.T. Applied zoology for forming of research competence at students of biologists // Handbook of research on students' research competence in modern educational contexts. Hershey. PA. USA: IGI Global, 2018. P. 321-341. D0I: 10.4018/978-1-5225-3485-3.ch017.

21. Клещева И.В. Оценка эффективности научно-исследовательской деятельности студентов. СПб.: НИУ ИТМО, 2014. 92 с. 